\title{
Exposição a agrotóxicos em agricultores do Movimento Sem Terra
}

\section{Exposition pesticides among brazilian land squatters}

\author{
Regina Rigatto Witt ${ }^{1}$ \\ Melissa Bueno Ambrosini²
}

\section{RESUMO}

Em 1993 agricultores do Movimento Sem-Terra ocuparam uma fazenda no sul do Brasil onde havia um depósito de agrotóxicos organoclorados. O objetivo desta investigação foi avaliar as condições de saúde dos agricultores expostos. Trata-se de um estudo epidemiológico do tipo descritivo transversal, com informação recordatória nos períodos: anterior ao acampamento (vida anterior a 1993), durante o acampamento (oito meses em 1993) e após o assentamento (até 1998). Para coleta dos dados foi elaborado um instrumento com questões de caracterização demográfica, história de exposição e de sinais e sintomas. Foram entrevistados 140 indivíduos trabalhadores adultos. A forma de exposição relatada foi o preparo, a aplicação dos produtos e/ou relato de trabalho em culturas determinadas. O desfecho estudado foram três ou mais sinais ou sintomas simultâneos após o relato de exposição. Os resultados apontam 16, 8 e 29 agricultores com relato compatível com o desfecho, antes, durante a ocupação e após o assentamento respectivamente. Os equipamentos de proteção individual foram rara e inadequadamente utilizados. Há evidências da necessidade de realização de estudos posteriores visando à compreensão dos efeitos da exposição aos agrotóxicos e indicam a necessidade da elaboração de programas educativos para serem desenvolvidos junto a agricultores para a prevenção das intoxicações.

\section{ABSTRACT}

In 1993 rural workers of a social movement occupied a farm in the south of Brazil where organoclorides pesticides were stored. This study was taken to evaluate health conditions of rural workers exposed to these organoclorides pesticides. This is a retrospective transversal study with collection of reminded data in the periods of: life before 1993, during the occupation in 1993 and after settlement in 1996. Demographic data, exposition, signs and symptoms were collected with the application of an instrument. Individuals (140) adults

\section{PALAVRAS-CHAVE:}

- Agrotóxico/ efeitos adversos;

- Saúde Ocupacional.

\section{KEY-WORDS:}

- Pesticides / adverse effects;

- Occupational Health.

\footnotetext{
${ }_{1}^{1}$ Professora Adjunta, Doutora em Enfermagem em Saúde Pública, USP. Universidade Federal do Rio Grande do Sul, RS, Brasil.

${ }^{2}$ Enfermeira, Hospital de Clínicas de Porto Alegre, Porto Alegre, RS, Brasil.
} 
workers were interviewed. The form of the exposure reported was the preparation and application of products and/or working in determinate cultures. The outcome studied was three or more simultaneous signs or symptoms after the report of exposure. Reports of 16 workers before 1993, 8 during occupation and 29 after 1996 were compatible with the outcome. Individual protection equipment were rarely and unadequately used. There are evidences of the need of further studies to elucidate health consequences of pesticides exposition and recommend the implementation of health education programs in order to prevent further poisoning on rural health workers.

\section{Introducão}

A Destilaria de Álcool Hidratado, na Fazenda Capela, município de Nova Santa Rita, que funcionou na década de 70 , possuía um depósito com várias toneladas de DDT (diclorodifenil-tricloroetano) e Aldrin, para uso no cultivo de cana de açúcar quando faliu. Em 1993, aproximadamente 1.200 pessoas ocuparam a área, acampando no interior e arredores do galpão, em cujo porão estavam armazenados os agrotóxicos.

Segundo depoimentos, uma das divisórias do galpão, que servia para abrigar máquinas agrícolas, estava cheia desse "pó marrom" embalados em sacos plásticos pequenos, alguns já rasgados e o veneno espalhado. Houve uso desses agrotóxicos para combater formigas e uma parte foi dada a agricultores de assentamentos vizinhos. Foram oito meses de ocupação até a posse definitiva da área. Hoje estão assentadas na área cem (100) famílias.

Em 1996, como conseqüência do trabalho da Universidade Federal do Rio Grande do Sul na área, o prefeito de Capela de Santana retirou uma parcela do agrotóxico que havia no depósito. Ao mesmo tempo profissionais e estudantes da área da saúde que aí atuavam resolveram realizar um estudo para avaliar as condições de saúde dos agricultores expostos a estes agrotóxicos durante ocupação da fazenda em 1993.

A problemática da contaminação ambiental por agrotóxicos, principalmente organoclorados, é bastante conhecida. Embora banidos há algum tempo em 1986 foram proibidos no estado do Rio Grande do Sul , seu uso clandestino, restos abandonados e estabilidade química continuam sendo um problema ambiental.

No que se refere a sua toxicologia, estabelecida por registro no Ministério da Agricultura, a grande maioria dos compostos deste grupo de inseticidas situa-se entre os princípios considerados de alta e regular toxicidade ${ }^{1}$. Todos os organoclorados apresentam um largo espectro residual, tendo também grande poder bioacumulativo. Pela potencialização que ocorre através das cadeias alimentares, o homem - no final dessa - vai acumulando esses agrotóxicos ou as lesões bioquímicas decorrentes destes, com conseqüências graves para sua saúde ${ }^{2}$.

Sua ação mutagênica e carcinogênica já foi comprovada em cobaias ${ }^{2,3}$. Discrasias sangüíneas diversas, inclusive aplasia medular foram descritas como algumas das conseqüências a longo prazo ${ }^{4}$.

Outra preocupação resulta do fato de os organoclorados serem sabidamente absorvidos através da pele intacta ${ }^{2,5,6}$, representando um grave 
risco, já que as pessoas não acreditam nessa possibilidade. Além de serem rápida e eficazmente absorvidos pelo trato gastrointestinal ${ }^{7}$.

As condições gerais de saúde dos trabaIhadores rurais também favorecem intoxicações. Aqueles com nível nutricional mais baixo ${ }^{2}$, como é o caso dos agricultores sem terra nos acampamentos, ou de pouca resistência física têm seu estado agravado 6 .

Além destes, os que voltam a trabalhar após um caso de intoxicação anterior ou em melhora clínica de outras doenças também estão mais propensos a uma nova intoxicação. Também crianças, como as que brincavam com os produtos na Fazenda Capela, estão entre os casos mais freqüentes de intoxicação, já que têm acesso a depósitos de inseticidas ${ }^{6}$.

\section{Metodologia}

Trata-se de um estudo epidemiológico do tipo descritivo transversal com informação recordatória. O local do estudo foi o Assentamento Capela de Santana. A população do estudo constituiu-se das famílias que aí acamparam. Estabeleceram-se critérios para escolha da amostra, residir atualmente no assentamento e ter idade mínima de 21 anos. Para a coleta de dados elaborou-se um instrumento com questões semiestruturadas. O procedimento utilizado foi a entrevista.

Procedeu-se a realização de um estudopiloto no município de Tapes, pois muitas das famílias assentadas nesse local estiveram acampadas na Fazenda Capela, em 1993.

Os entrevistadores foram estudantes de graduação dos cursos de enfermagem, agronomia e biologia da UFRGS. Para padronização do trabalho dos entrevistadores, organizou-se uma capacitação onde os temas contaminação do meioambiente, exposição e intoxicação por organoclorados e metodologia de aplicação do instrumento foram abordados.

Para codificação do banco de dados utilizouse o Programa Excel 2003. Os questionários foram revisados e os dados digitados.

Definição da variável dependente: sinais e sintomas.

Pela dificuldade de acesso a serviços de saúde e pela baixa procura aos mesmos na zona rural, raros foram os casos de intoxicação aguda diagnosticados em postos de saúde ou hospitais. Devido a isso, para determinação de casos de intoxicação aguda utilizamos os seguintes passos para a investigação4.

Anamnese clínica: coletar dados de sintomas comportamentais específicos ou relacionados ao sistema nervoso central.

História ocupacional: pesquisar as atividades laborativas exercidas desde o início da carreira laboral; pesquisar os prováveis contatos com agrotóxicos (duração e periodicidade de exposição, tipo de contato, quantidade de produto utilizada, uso de equipamento de proteção, disposição de resíduos e destino de embalagem, assim como condições climáticas, de saneamento e recursos hídri$\cos )$.

Definição das variáveis independentes:

As entrevistas objetivaram determinar as pessoas que estiveram expostas no depósito, que tiveram algum tipo de contato com o composto organoclorado estocado na fazenda e os problemas de saúde apresentados por essa população. 
Foram considerados expostos ao agrotóxico estocado na fazenda todos os que moraram no depósito, manusearam o veneno para combater formigas ou com outro objetivo, os indivíduos, principalmente crianças, que circulavam no galpão e pessoas que lavaram roupas que estiveram em contato com o agrotóxico.

Ainda foram investigados fatos relevantes da vida pregressa dos entrevistados como região de origem, exposições anteriores a agrotóxicos de qualquer natureza, tipo de cultura em que já trabalharam. Dados demográficos de interesse para o estudo, como idade e escolaridade também foram coletados.

\section{Resultados e Discussão}

A maioria dos 140 indivíduos avaliados encontrou-se na faixa etária entre 21 e 62 anos, com um indivíduo de 99 anos. Eram 72 do sexo masculino, 69 do sexo feminino. A maior parte (94) estudou de 2 a 5 anos completos. Esta característica é relatada pela literatura como tendo relação com as intoxicações por agrotóxicos pois, segundo Guerra et al. $^{8}$, verifica-se um maior índice de intoxicações nas regiões menos desenvolvidas provocadas, não apenas pelo alto grau de analfabetismo, como também pela desinformação sobre os riscos que os pesticidas agrícolas representam. A seguir, apresentaremos os resultados relativos à exposições ocorridas antes e durante o acampamento e após o assentamento.

\section{III.1. Antes do acampamento}

Antes do acampamento 132 entrevistados trabalhavam na agricultura. Os municípios de origem pertencem às regiões do Alto Uruguai e
Missões (100\%), onde cultivavam soja $(87,2 \%)$ e milho $(84,3 \%)$. Com relação ao uso de agrotóxicos, 66 entrevistados referiram utilizá-los antes do assentamento. O tempo de uso de agrotóxicos antes do acampamento foi de até 5 anos para 32 entrevistados, e de 6 a 10 anos para 10 deles. Os produtos mais utilizados neste período foram o Aldrin (15), DDT (12) (organoclorados) e Karate (12), sendo que dez agricultores não souberam informar o produto utilizado. Sabe-se que os agrotóxicos do tipo organoclorados dos grupos Aldrin e DDT eram usados massivamente nesta região no combate a pragas nas culturas de milho e soja anteriormente a sua proibição e, por isso, é possível que os outros 66 , que referiram não utilizá-los, tenham tido contato com os produtos citados.

\section{Gráfico 1. Sintomas referidos com exposição a agrotóxicos no período anterior a 1993:}

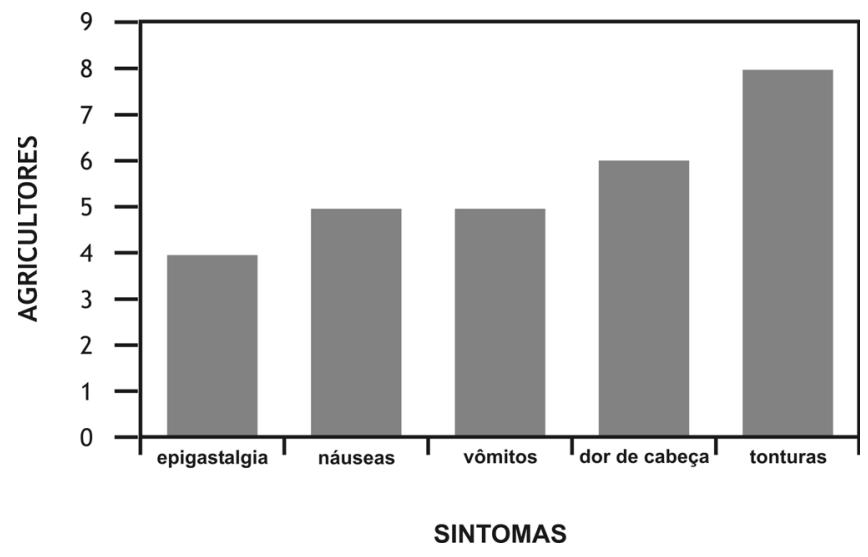

Dezesseis entrevistados relataram sinais e sintomas, sendo que 9 destes relataram pelo menos 3 sintomas de intoxicação e história ocupacional compatível. Os demais casos foram diagnosticados no hospital ou posto de saúde. Os sintomas (gráfico 1) manifestaram-se quando os agricultores aplica- 
vam agrotóxicos (7) ou trabalhavam na lavoura após a aplicação (7). Dos agricultores que usavam agrotóxico, o tipo de contato que tiveram pode ser visto no gráfico 2 .

Gráfico 2. Tipo de contato com agrotóxicos no período anterior a 1993:

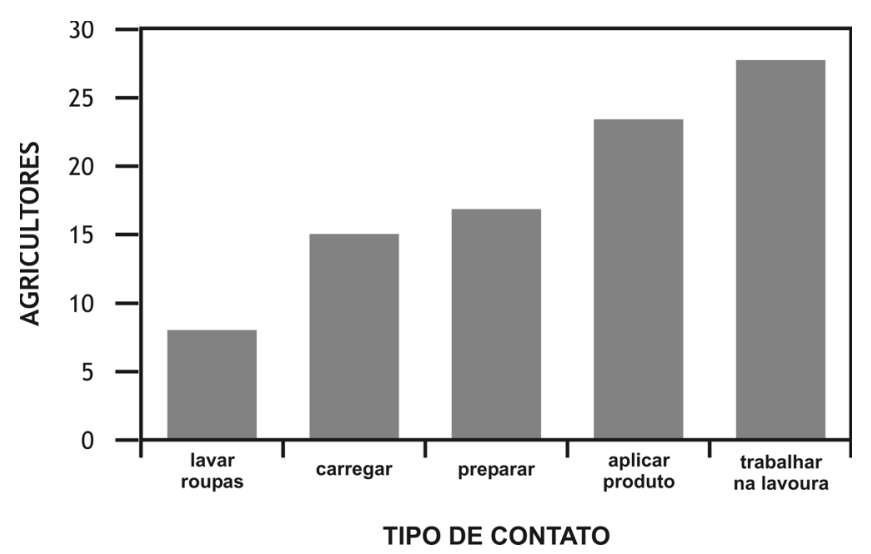

As medidas de proteção (gráfico 3) relatadas mostraram-se insuficientes. Estas práticas podem estar relacionadas ao fato de os agricultores não acreditarem na toxicidade dos produtos, assim como na dificuldade do uso de equipamento apropriado, já que é muito desconfortável em temperaturas elevadas. Sabe-se que os ciclodienos (Aldrin, Dieldrin, Endrin) assumem grande importância na absorção através da pele intacta ${ }^{5,6}$, representando um grave risco. A via respiratória também assume importância neste caso, pois os agrotóxicos podem ser inalados quando os produtos são pulverizados, o que deve ter sido o caso dos agricultores que relataram aplicação de formulações líquidas.

\section{Gráfico 3. Uso de equipamentos de proteção individual antes de 1993:}
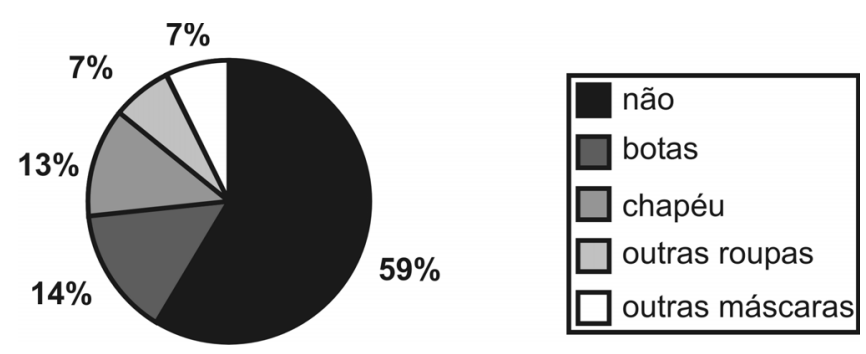

\section{III.2. Durante a ocupação}

Durante a ocupação da Fazenda Capela, 22 agricultores relataram que acamparam no galpão, sendo que 13 destes ficaram no porão, onde estavam armazenados os produtos organoclorados. Outros 18 agricultores acamparam em barracas ao redor do galpão e, 36 em barracas distantes do galpão mais de 20 metros. O tempo de permanência foi de três a seis meses (46). A maioria dos agricultores relatou saber da existência do depósito de agrotóxicos, sendo que 75 sentiram o cheiro forte do produto. Alguns também manusearam o produto (36).

Relataram sinais e sintomas 8 agricultores, sendo que o sintoma mais referido foi de dor de cabeça persistente (6).

\section{III.3. Após o assentamento}

Após 1996 as culturas mais plantadas foram: mandioca (63), melão (52), milho (50), feijão (42), arroz (37), batata-doce (27), melancia (25), pastagens (16).

Agrotóxicos foram utilizados por 65 agricultores. Dos 75 restantes, 24 relataram uso de agrotóxicos durante algum tempo após o assentamento e, à época do levantamento, não mais utiliza- 


\section{Gráfico 4. Sintomas referidos por exposição a} agrotóxicos após o assentamento:

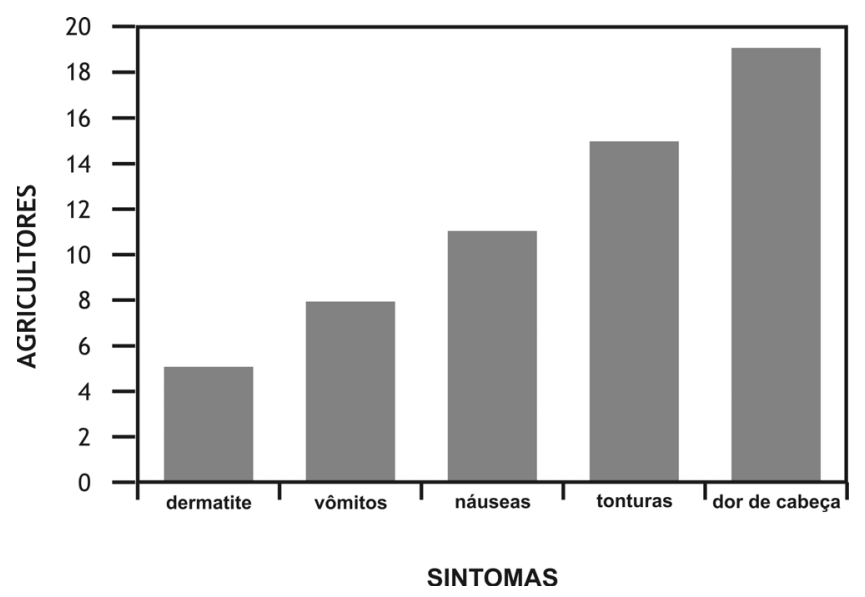

vam. O tempo médio de contato com estes produtos foi 2,6 anos. Os sinais e sintomas (gráfico 4) após a exposição ocorreram quando os agricultores aplicavam agrotóxicos (11) ou trabalhavam na lavoura após a aplicação (10). Os produtos mais utilizados foram Karate (35), Cercobin (19), Neguvon (19) e Arrozan (11). O tipo de contato mais freqüente com estes produtos encontra-se no gráfico 5 . As medidas de proteção apresentadas no gráfico 6 mostraram-se inadequadas.

\section{Gráfico 5. Tipo de contato com agrotóxicos} após o assentamento:

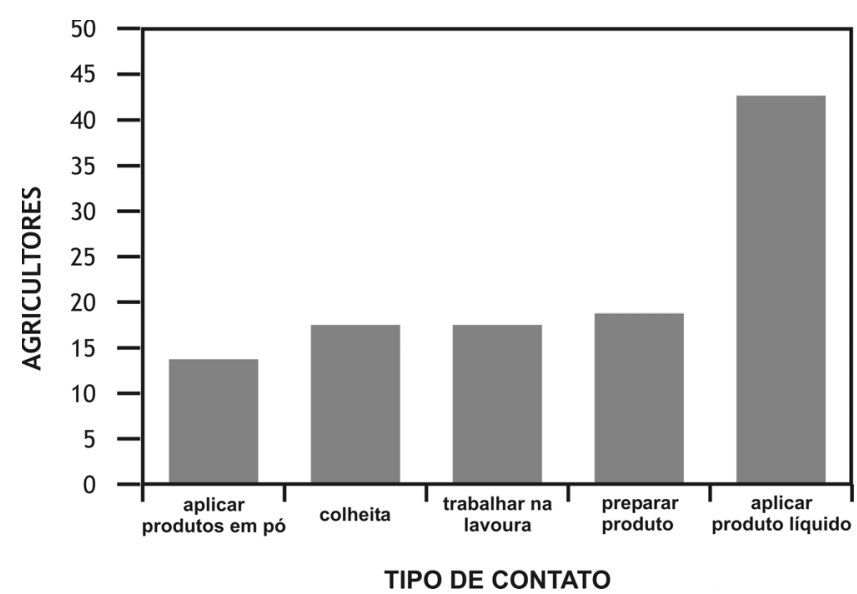

Gráfico 6. Uso de equipamentos de proteção individual após o assentamento:
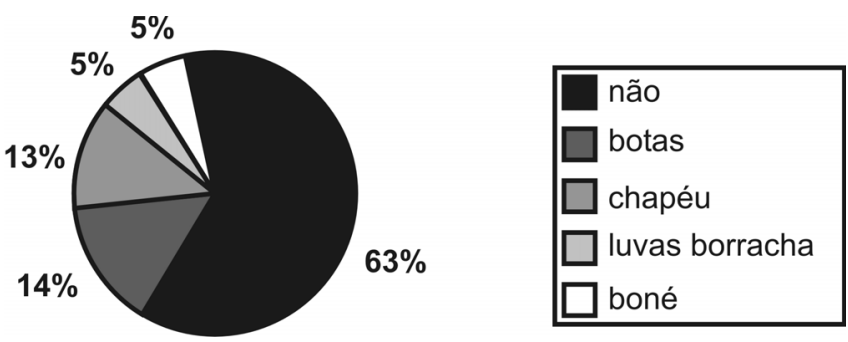

\section{Conclusão}

Conclui-se que nesta população, dos expostos no período anterior ao acampamento (trabalhavam na agricultura e usavam agrotóxicos), $11 \%$ relataram sinais e sintomas compatíveis com o desfecho. Durante o acampamento, esta situação foi relatada por $9 \%$ dos expostos (acamparam na fazenda) e após o assentamento, por $33 \%$ dos expostos (trabalhavam na agricultura e usavam agrotóxicos).

A identificação de sinais e sintomas com utilização de vários tipos de produtos nos três períodos estudados aponta a necessidade de estudos posteriores visando identificar os efeitos das múltiplas exposições.

Durante o estudo, foram identificadas variáveis que podem estar relacionadas com estes resultados, quais sejam: a pouca e inadequada utilização de equipamentos de proteção individual, como também a baixa escolaridade desta população. Recomenda-se a realização de estudos posteriores para determinar o nível de associação, como também a realização de programas educativos visando a prevenção das intoxicações.

O reduzido número de agricultores entrevistados com diagnóstico médico de intoxicação indica a necessidade de preparo dos profissionais de 
saúde, principalmente os da zona rural para o diagnóstico.

\section{Referências}

1. Caveiro E et al. Manual de Inseticidas e Acaricidas - Aspectos Toxicológicos. Pelotas: Aiamara; 1976. 2. Ruegg EF et al. Impacto dos Agrotóxicos Sobre o Ambiente a Saúde e a Sociedade. São Paulo: Cone;1986.

3. Pinheiro S, Nasr NY, Luz D. AAgricultura Ecológica e a Máfia dos Agrotóxicos no Brasil. Porto Alegre: Fundação Juquira Candiru; 1993.

4. Organização Pan-Americana de Saúde / Organização Mundial de Saúde/UNICAMP. Proposta de uma Metodologia para Implantação de um Sistema de vigilância a Saúde de Populações Expostas a Agrotóxicos em Cinco Estados do Brasil - Relatório Final. Brasília: Ministério da Saúde; 1996. 5. Ministério da Saúde. Informações Médicas de Urgência nas Intoxicações por Produtos Agrotóxicos. Brasília: Ministério da Saúde; 1996. 6 Marconi, FAM. Inseticidas e seu Emprego no Combate às Pragas. São Paulo: Livraria Nobel; 1983.

7.Larini L. Toxicologia, São Paulo: Manole; 1987.

8.Guerra M., Sampaio DPA. Receituário Agronômico. Rio de Janeiro: Globo; 1988.

\section{Endereço para correspondência:}

Regina Rigatto Witt

Rua Lusitana 835 apt 304

Porto Alegre - RS CEP 90520-080

\section{Endereço eletrônico:}

witt@adufrgs.ufrgs.br 